\title{
Employee Resistance To Organizational Change
}

Justin Bateh, MBA, Florida State College at Jacksonville, USA

Mario E. Castaneda, EdD, California State University at Los Angeles, USA

James E. Farah, DBA, JD, Jacksonville University, USA

\begin{abstract}
As change management becomes an essential ingredient of organizations' performance, the body of literature describing successful and unsuccessful change management initiatives continues to expand. Numerous articles and studies provide an insight into the nature of change management and its most common pitfalls. The most recurring themes include resistance to change, readiness for change, leadership effectiveness, employee commitment and participation in change initiatives, and the roles and competencies needed to ensure the success of strategic change. The present article focuses on one of these themes: resistance to change. Understanding of resistance may enable managers to reduce conflict and increase collaboration. To meet these challenges, leaders must be trained and educated to overcome resistance to change. This article points out important types of resistance for organizations to address.
\end{abstract}

Keywords: Change Management; Organizational Change; Resistance to Change

\section{STATEMENT OF THE PROBLEM}

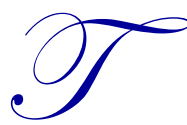

oday's research indicates that between $30 \%$ and $60 \%$ of all change initiatives within organizations fail (Gilley et al., 2009a, 2009b). Some researchers report even more pessimistic results, suggesting rates of change failure at $80 \%$ to $90 \%$, according to Gilley et al. Change is complex and often unpredictable. Even a well-planned organizational change strategy may have unintended consequences (Jian, 2007). It is widely assumed that resistance to change impedes the development of successful change strategies (Gilley et al., 2009a, 2009b).

In the context of change management research, the issue of resistance occupies a crucial place. Organizations should be aware of the human element and its implications for the success of all change management decisions. The success of change management depends upon the organizational structure, availability of resources, vision and mission of the organization, and employees' willingness to work towards the change-related goals (Brisson-Banks, 2010). Managers who ignore this last element guarantee themselves an uphill battle, if not a sure failure.

\section{REASONS FOR RESISTANCE}

Many employees, even at the management level, may lack the experience and motivation to recognize the urgency of change (Erwin, 2009). Ford, Ford, and D'Amelio (2008) wrote that resistance to change grows from broken agreements and trust violations. This line of research suggests that organizations which manage to repair broken relationships quickly are less likely to face resistance (Ford et al., 2008). At the later stages of change implementation, resistance to change and anxiety about job stability and growth become overarching (Erwin, 2009). Many employees fear that they will not be fortunate enough to retain their jobs, whereas others are simply unwilling or unprepared to learn and develop new skills, according to Erwin.

Communication breakdowns further contribute to resistance in changing organizations (Ford et al., 2008). Resistance by itself suggests that those affected by pending or ongoing changes are aware of their organization's 
needs and, most likely, discuss the benefits and drawbacks of the changes. According to Ford et al., resistance indicates that change recipients do talk about change and its potential consequences. These authors noted that resistance has a considerable engagement value, and may even reflect a higher level of commitment, rather than unthinking acceptance. Resistance can also be interpreted as a form of conflict that can potentially improve the quality of organizational decisions (Ford et al., 2008), if appropriate avenues of communication are provided. These suggestions deny the validity of the previous assumptions about resistance. It appears that it is not resistance per se but the way organizations perceive resistance that either impedes or facilitates change. Simultaneously, the debate surrounding the issue of change should not be ignored. Managers must be prepared to talk candidly about the needs for change, otherwise fear and uncertainty will remain a prevailing element that can damage morale and prevent successful implementation of the desired changes at all levels of the organization.

\section{PROMOTING CHANGE READINESS}

While pending changes can generate acute reactions in changing organizations, employees are also interested in the way change readiness can benefit them. Change readiness, as the opposite of resistance, is another concept that continues to generate professional disagreements. To date, readiness has been considered the fundamental precursor for implementing and managing productive change (Weiner, 2009). The concept of change readiness finds its reflection in Lewis's model of organizational change, which requires that organizations first unfreeze the existing mindsets and develop the sense of urgency, before the change is actually set in motion for implementation, according to Weiner.

The role of individual competencies, the potential contribution of employees to make positive change, as well as the role of individual learning make up a considerable share of present-day organizational change knowledge and research (Avey, Wernsing, \& Luthans, 2008; Bercovitz \& Feldman, 2008; Luscher \& Lewis, 2008). Certainly, the quality of individual-level adaptation in organizational change cannot be easily dismissed, and its significance is further justified by the fact that, in organizational change environments, actors naturally seek to make sense of the situation and adjust their expectations to the new experiences emerging as a result of the change (Bercovitz \& Feldman, 2008). However, organizations should not overestimate the importance of individually-driven factors of change readiness.

Some employees are more loyal to relationships, while others are more loyal to structural components of an organization, which are often based on principles such as efficiency, tradition, or creating an acceptable fit with partnering organizations. Most often, both elements need to be addressed during organization change. To facilitate employee readiness and overcome resistance, some employees need to know that personnel are treated fairly during the process, while others are more concerned with the logic of the decision-making around the need for structural change. For those employees who are more concerned with relationships, to facilitate their readiness and overcome resistance, they need to be convinced that certain personnel changes are necessary and will be made as respectfully and fairly as possible. The employees concerned with structure may question whether change is necessary and useful, or alternately whether it is simply the whim of some high level administrators who want to make their mark without full consideration of the implications. These employees are more likely to take a stance that change may offer few benefits but many hindrances. They are more likely to accept change if they can be convinced that the short-term challenges will allow for long-term benefits. To ensure their buy-in to the change process, they must be convinced that the long-term benefits will more than compensate them for the short-term distruptions and inefficiencies inherent in the change process.

\section{LEADERSHIP STYLE DURING ORGANIZATIONAL CHANGE}

The role of leadership in driving or impeding organizational change remains one of the major subjects of professional debate in organizational change research. The significance of the concept is justified by the fact that leadership effectiveness has direct impacts on organizations' change capabilities (Gilley et al., 2009a, 2009b). Numerous variables affect leaders' effectiveness, and these variables can facilitate or impede change implementation within organizations (Gilley, McMillan, \& Gilley, 2009). Leaders' failure to establish clear norms of change readiness and develop a comprehensive change vision can readily reduce organizations' and units' capabilities to implement and manage change (Caldwell, Chatman, O'Reilly, Ormiston, \& Lapiz, 2008). The 
change process cannot be resolved at individual decision-making levels, but needs clear direction from leadership at many levels of management (Sandelands, 2010). Organizational change should not be left to proceed in an obscure and unsystematic way on any level of the organization.

Herold, Fedor, Caldwell, and Liu (2008) suggested that transformational leadership is strongly indicitive of effectiveness of organizational change. Although much remains to be established about the role of leadership in the change process, organizations with weak leadership will most likely face tough challenges in their striving to implement change. Organizational change has been a tough topic to pin down due to the complexity of the enormous number of elements that interact during the change process. To a large extent, at the present time organization leaders must themselves determine how ready they are for change and what factors are likely to prevent them from meeting their goals.

\section{RECOMMENDATION FOR FUTURE RESEARCH}

Researchers have focused on the individual level of change readiness and rarely proceed to analyze readiness at the organizational level (Weiner, 2009). As of today, it is not clear whether organizations, their departments, and units vary in their capabilities to implement and manage changes (Caldwell et al., 2008). It is not clear which factors are the most important for change readiness. That readiness is essential for successful change cannot be denied, but how and whether at all readiness can be measured remains an issue of concern (Weiner, 2009). Weiner noted that "in the absence of theoretical clarification and exploration of these issues, efforts to advance measurement, produce cumulative knowledge, and inform practice will likely remain stalled" (p. 2).

Although Herold et al. (2008) suggested that transformational leadership is strongly indicitive of effectiveness of organizational change, how exactly leadership and organizational change interact remains unclear. The study of challenges and barriers to change management and implementation is far from systematic. Organizations do have some knowledge of the most important factors of organizational change but lack practical guidance to use them in real-life situations. Moreover, the picture of the factors impeding organizational change implementation lacks coherence and completeness. Even though it is known that resistance, change readiness, and leadership have the potential to speed up, slow down, facilitate, or hinder the process of change, how these factors interact remains unclear.

\section{CONCLUSION}

In today's competitive markets, organizations must be able to change to adapt to changing market conditions, but change must be productive and cost-effective. By understanding which factors impede or hinder the development of change management initiatives, firms will have better chances to avoid the major pitfalls associated with change. Researchers continually identify resistance to change as one major challenge. Employees need comprehensive information about the nature, processes, and consequences of organizational change. These attributes are important for educators to convey to students, both to prepare personnel for change and overcome resistance, but also to create the kind of readiness and buy-in that make employees active contributors to the success of organizational change.

\section{AUTHORS' INFORMATION}

Justin Bateh is a business educator and practitioner who has been a faculty member at higher education institutions and a multidisciplinary consultant in small to mid-sized companies. He has an MBA from Nova Southeastern University and is a Doctor of Business Administration candidate at Walden University. He has developed professional and continuing education courses for healthcare professionals, and taught both undergraduate and graduate business courses in higher education institutions. Currently, he is an Assistant Professor of Business at Florida State College at Jacksonville. Mr. Bateh's areas of interest include operations management, organization development, leadership, job satisfaction, quantitative decision making, multicultural management, and technology innovation. E-mail: jbateh@fscj.edu (Corresponding author) 
Mario E. Castaneda is an educational practitioner who has been a teacher, counselor, coordinator, and curriculum and staff development specialist. He has a doctoral degree in Education and Organizational Leadership from Pepperdine University and is currently a Professor of Education at California State University in Los Angeles. He has an MA in International and Multicultural Education from the University of San Francisco. He has taught both pre- and post-service teachers at various universities and colleges throughout California and Colorado. Dr. Castaneda's areas of interest include social sciences, second language acquisition, sheltered English for the secondary classroom, and cross-cultural and multicultural education. Dr. Castaneda's research has explored the social and educational success of the Central American community, the African legacy of Central America, issues of inter-group relations between ethnic minority groups, and museum community outreach programs for the Latino Community.

James E. ("Jim") Farah. His professional career spans over the past 30 years, which includes working for United Parcel Service for 20 years. Jim currently serves as general counsel for businesses in Florida. Jim has earned the following degrees: Doctorate of Business Administration, Juris Doctorate, Masters of Business Administration, and a Bachelor of Science. Jim has taught at the graduate level for many years and his research has been focused on the area of job satisfaction. He currently serves as an adjunct faculty member at Jacksonville University and the Florida Coastal School of Law instructing in the areas of business and law.

\section{REFERENCES}

1. Avey, J. B., Wernsing, T. S., \& Luthans, F. (2008). Can positive employees help positive organizational change? Journal of Applied Behavioral Science, 44(1), 48-70.

2. Bercovitz, J., \& Feldman, M. (2008). Academic entrepreneurs: Organizational change at the individual level. Organization Science, 19(1), 69-89.

3. Brisson-Banks, C. V. (2010). Managing change and transitions: A comparison of different models and their commonalities. Library Management, 31(4), 241-252.

4. Caldwell, D., Chatman, J., O’Reilly, C., Ormiston, M., \& Lapiz, M. (2008). Implementing strategic change in a heath care system: The importance of leadership and change readiness. Health Care Management Review, 33(2), 124-133.

5. Erwin, D. (2009). Changing organizational performance: Examining the change process. Hospital Topics: Research and Perspectives on Healthcare, 87(3), 28-40.

6. Ford, J. D., Ford, L. W., \& D'Amelio, A. (2008). Resistance to change: The rest of the story. Academy of Management Review, 33(2), 362-377.

7. Gilley, A., Gilley, J. W., \& McMillan, H. S. (2009). Organizational change: Motivation, communication, and leadership effectiveness. Performance Improvement Quarterly, 21(4), 7-94.

8. Gilley, A., McMillan, H. S., \& Gilley, J. W. (2009). Organizational change and characteristics of leadership effectiveness. Journal of Leadership \& Organizational Studies, 16(1), 38-47.

9. Herold, D. M., Fedor, D. B., Caldwell, S., \& Liu, Y. (2008). The effects of transformational and change leadership on employees' commitment to a change: A multilevel study. Journal of Applied Psychology, 93(2), 346-357.

10. Jian, G. (2007). Unpacking unintended consequences in planned organizational change: A process model. Management Communication Quarterly, 21(5), 5-28.

11. Luscher, L. S., \& Lewis, M. W. (2008). Organizational change and managerial sensemaking: Working through paradox. Academy of Management Journal, 51(2), 221-240.

12. Sandelands, L. (2010). The play of change. Journal of Organizational Change Management, 23(1), 71-86.

13. Weiner, B. J. (2009). A theory of organizational readiness for change. Implementation Science, 4, 1-9. 